\title{
A New Statistical-Based Correlation for the Rib Fin Effects on the Overall Heat Transfer Coefficient in a Rib-Roughened Cooling Channel
}

\author{
M. E. Taslim ${ }^{1}$ and V. Nezym ${ }^{2}$ \\ ${ }^{1}$ Mechanical and Industrial Engineering Department, Northeastern University, Boston, MA 02115, USA \\ ${ }^{2}$ SPEI ESIME Culhuacan, National Polytechnic Institute, Av. Santa Ana 1000, Col. San Francisco Culhuacan, \\ Deleg. Coyoacan, 04430 Mexico DF, Mexico
}

Received 8 January 2007; Accepted 10 July 2007

Recommended by J. C. Han

\begin{abstract}
Heat transfer coefficients in the cooling cavities of turbine airfoils are greatly enhanced by the presence of discrete ribs on the cavity walls. These ribs introduce two heat transfer enhancing features: a significant increase in heat transfer coefficient by promoting turbulence and mixing, and an increase in heat transfer area. Considerable amount of data are reported in open literature for the heat transfer coefficients both on the rib surface and on the floor area between the ribs. Many airfoil cooling design software tools, however, require an overall average heat transfer coefficient on a rib-roughened wall. Dealing with a complex flow circuit in conjunction with $180^{\circ}$ bends, numerous film holes, trailing-edge slots, tip bleeds, crossover impingement, and a conjugate heat transfer problem; these tools are not often able to handle the geometric details of the rib-roughened surfaces or local variations in heat transfer coefficient on a rib-roughened wall. On the other hand, assigning an overall area-weighted average heat transfer coefficient based on the rib and floor area and their corresponding heat transfer coefficients will have the inherent error of assuming a $100 \%$ fin efficiency for the ribs, that is, assuming that rib surface temperature is the same as the rib base temperature. Depending on the rib geometry, this error could produce an overestimation of up to $10 \%$ in the evaluated rib-roughened wall heat transfer coefficient. In this paper, a correction factor is developed that can be applied to the overall area-weighted average heat transfer coefficient that, when applied to the projected rib-roughened cooling cavity walls, the net heat removal from the airfoil is the same as that of the rib-roughened wall. To develop this correction factor, the experimental results of heat transfer coefficients on the rib and on the surface area between the ribs are combined with about 400 numerical conduction models to determine an overall equivalent heat transfer coefficient that can be used in airfoil cooling design software. A well-known group method of data handling (GMDH) scheme was then utilized to develop a correlation that encompasses most pertinent parameters including the rib geometry, rib fin efficiency, and the rib and floor heat transfer coefficients.
\end{abstract}

Copyright ( $) 2007$ M. E. Taslim and V. Nezym. This is an open access article distributed under the Creative Commons Attribution License, which permits unrestricted use, distribution, and reproduction in any medium, provided the original work is properly cited.

\section{INTRODUCTION}

Serpentine cooling channels within turbine airfoils are usually roughened with ribs. These ribs increase the level of mixing of the cooler core air with the warmer air close to the channel wall and restart the boundary layer after flow reattachment between ribs resulting in enhanced convective heat transfer coefficients. Experimental results, reported by many investigators, show as high as a five-fold enhancement in heat transfer coefficients of rib-roughened surfaces when compared with those of smooth (nonribbed) channels. Geometric parameters such as channel aspect ratio (AR), rib height-to-passage hydraulic diameter $\left(e / D_{h}\right)$ or blockage ra- tio, rib angle of attack $(\alpha)$, the manner in which the ribs are positioned relative to one another (inline, staggered, crisscross, etc.), rib pitch-to-height ratio $(P / e)$, and rib shape (round versus sharp corners, fillets, rib aspect ratio $\left(\mathrm{AR}_{\mathrm{rib}}\right)$, and skewness towards the flow direction) have pronounced effects on both local and overall heat transfer coefficients. Considerable data are available on both the heat transfer coefficient on the passage surface between the ribs and on the rib surfaces. Some of these effects were studied by different investigators such as Abuaf et al. [1], Burggraf [2], Chandra et al. [3], Chandra and Han [4], Han et al. [5-8], Liou et al. $[9,10]$, Metzger et al. [11-13], Taslim et al. [14-18], Taslim and Wadsworth [19], Korotky and Taslim [20], Taslim 
and Korotky [21], and Taslim and Lengkong [22, 23] and Webb et al. [24]. These studies show a considerable variation in heat transfer coefficient from the surface area between the ribs to the rib forward, top, and aft surfaces. Most of the software tools for the design of airfoil cooling circuits, however, have no provisions to handle either the geometric details of the ribs or the variations in heat transfer coefficients along the rib-roughened surface. Therefore, the airfoil cooling circuit designer is limited to assign an equivalent heat transfer coefficient on channel surface that accounts for the area enhancement, heat transfer coefficient variations, and the rib fin effects. Heat transfer area enhancement is a purely geometric analysis that is presented in this paper for a variety of rib geometries. Variations in heat transfer coefficient on the area between the ribs $\left(h_{\text {floor }}\right)$ and on the rib surface itself $\left(h_{\text {rib }}\right)$ are available for a wide range of rib geometries in open literature. Thus, an area-weighted average heat transfer coefficient is easily evaluated for a wide range of rib geometries. This area-weighted average heat transfer coefficient, however, is based on the approximation that the entire rib surface is at the same temperature as the rib base, that is, a $100 \%$ fin efficiency is assumed for the ribs. These ribs at the same time do not fall into the classic fin category for which the overall fin efficiencies are readily available. Therefore, the main objective of this investigation was to generate a correlation for the rib fin effect corrections that encompasses all common rib geometric parameters as well as the common hot and cold side flow conditions.

\section{DERIVATIONS}

Details of the geometric derivations are reported in Taslim [25]. For a repeated computational domain with a length of $P$ (rib pitch) that includes a rib and half of the floor surface on each side of the rib, as shown in Figure 1, the heat transfer areas are

$$
\begin{aligned}
A_{\text {base }}=\left[w_{\text {bot }}+2 r_{\text {fillet }} \tan (\beta / 2)\right] a / \sin (\alpha) \\
\text { rib base (projection) area, }
\end{aligned}
$$

$$
\begin{aligned}
A_{\text {floor }}=\left\{P-\left[w_{\text {bot }}+2 r_{\text {fillet }} \tan (\beta / 2)\right] / \sin (\alpha)\right\} a \\
\text { surface area between a pair of ribs, }
\end{aligned}
$$

$$
\begin{aligned}
A_{\text {rib }}=\left\{2\left[(e / \sin \beta)-r_{\text {top }} \tan (\beta / 2)-r_{\text {fillet }} \tan (\beta / 2)\right]\right. \\
\left.+\left[w_{\text {top }}-2 r_{\text {top }} \tan (\beta / 2)\right]+2\left(r_{\text {top }}+r_{\text {fillet }}\right) \beta\right\} a / \sin (\alpha) \\
\text { rib exposed area. }
\end{aligned}
$$

The equivalent heat transfer coefficient for a rib is defined as a heat transfer coefficient that, when applied on the base surface of the rib (projection surface), will have the same thermal effects as that of the actual heat transfer coefficient applied on all rib exposed surfaces, that is,

$$
A_{\text {rib }} h_{\text {rib }}=A_{\text {base }} h_{\text {equiv }} .
$$

Substituting for these areas from (1) through (3) and normalizing all rib dimensions with the rib height, $e$, we have

$$
\begin{aligned}
h_{\text {equiv }}=h_{\text {rib }}\left\{2\left[(1 / \sin \beta)-\left(r_{\text {top }} / e+r_{\text {fillet }} / e\right) \tan (\beta / 2)\right]\right. \\
+\left[\left(w_{\text {top }} / e\right)-2\left(r_{\text {top }} / e\right) \tan (\beta / 2)\right] \\
\left.+2 \beta\left(r_{\text {top }} / e+r_{\text {fillet }} / e\right)\right\} / \\
{\left[\left(w_{\text {bot }} / e\right)+2\left(r_{\text {fillet }} / e\right) \tan (\beta / 2)\right] . }
\end{aligned}
$$

The overall heat transfer coefficient is the area-weighted average of the surface between a pair of ribs (floor) and the rib equivalent heat transfer coefficient, that is,

$$
A_{\text {floor }} h_{\text {floor }}+A_{\text {base }} h_{\text {equiv }}=h_{\text {overall }}(\mathrm{Pa}),
$$

where $\mathrm{Pa}$ is the projection area associated with one rib that is the area representing the airfoil cooling cavity surface in most airfoil cooling design software tools. Upon substitution for areas and heat transfer coefficients from (1) through (5) with simplifications,

$$
\begin{aligned}
h_{\text {overall }}=h_{\text {rib }}\{ & \left\{(1 / \sin \beta)-\left(r_{\text {top }} / e+r_{\text {fillet }} / e\right) \tan (\beta / 2)\right] \\
& +\left[\left(w_{\text {top }} / e\right)-2\left(r_{\text {top }} / e\right) \tan (\beta / 2)\right] \\
+ & \left.2 \beta\left(r_{\text {top }} / e+r_{\text {fillet }} / e\right)\right\} /[(P / e) \sin \alpha] \\
+ & h_{\text {floor }}\left\{(P / e)-\left[\left(w_{\text {bot }} / e\right)+2\left(r_{\text {fillet }} / e\right) \tan (\beta / 2)\right] /\right. \\
& \sin (\alpha)\} /(P / e) .
\end{aligned}
$$

\subsection{Correction for the rib fin effects}

In applying the $h_{\text {equiv }}$ to the rib-roughened projection area on the cooling channel surface, it is assumed that the entire rib surface is at its base temperature. In other words, the rib fin effects are neglected. This assumption may not introduce any significant error for small blockage ratio ribs arranged at high pitch-to-height ratios. However, for high aspect and blockage ratio ribs, the error in the overall heat transfer coefficient can be as high as $20 \%$. To investigate these effects, twodimensional models of several rib geometries were meshed and numerically analyzed for a range of pertinent parameters and realistic boundary conditions. Three-dimensional models are also under investigations that will be reported in the future. The objective is to determine a correction factor that when is multiplied by $h_{\text {equiv }}$, it gives the final heat transfer coefficient, $h_{\text {corrected }}$, that goes into airfoil cooling design software tools.

\subsection{Numerical models}

Figure 2 shows the actual airfoil cooling cavity wall (on the left) and the simplified equivalent wall used in design software tools (on the right). The total heat transfer rate per unit depth from the hot to the cold side for the simple slab case is readily evaluated as

$$
\begin{aligned}
\dot{Q}_{\text {design }} & =\frac{P\left(T_{\text {hot }}-T_{\text {cold }}\right)}{\left(1 / h_{\text {hot }}\right)+\left(t_{\text {wall }} / k_{\text {metal }}\right)+\left(1 / h_{\text {corrected }}\right)} \\
& =\frac{P\left(T_{\text {hot }}-T_{\text {cold }}\right)}{R_{\text {hot }}+R_{\text {wall }}+R_{\text {corrected }}} .
\end{aligned}
$$




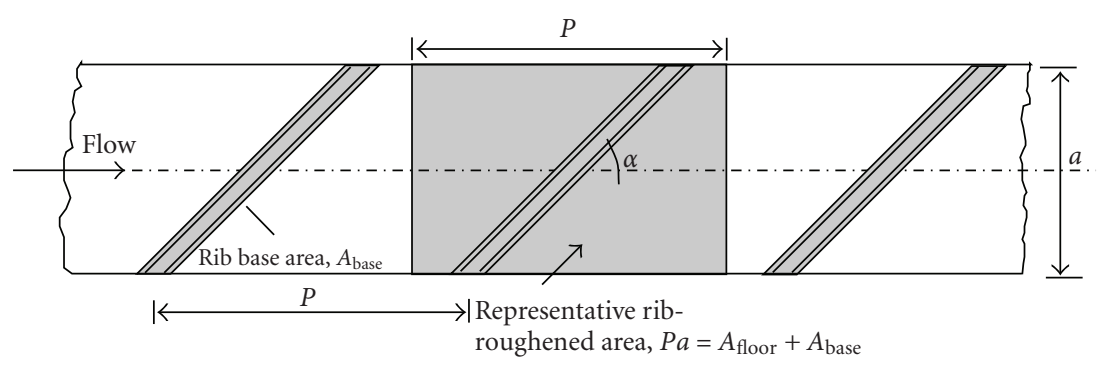

(a)

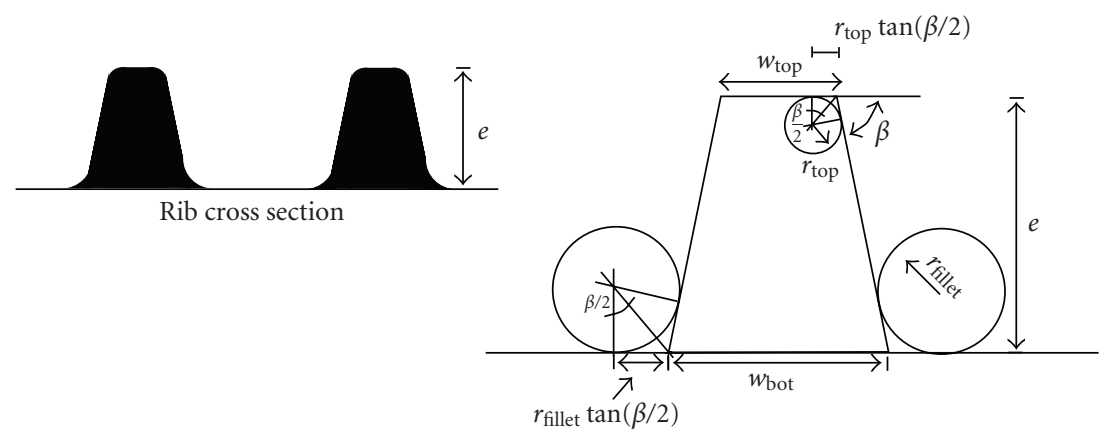

(b)

FIGURe 1: A typical rib geometry.
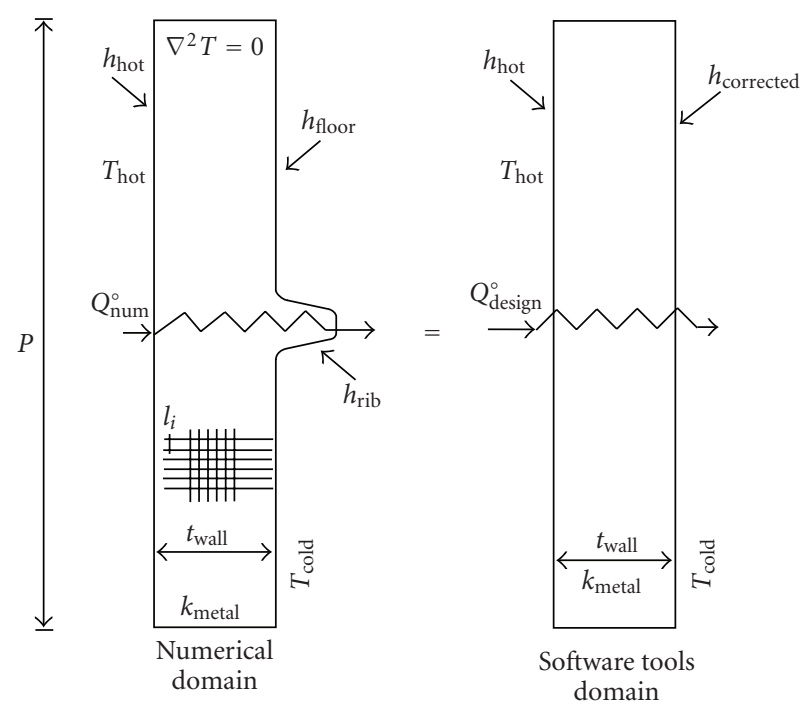

FIGURE 2: Equivalent thermal circuits.

The total heat transfer rate from the gas to the coolant side for the actual cooling cavity wall, however, was determined numerically. A finite element package was used to solve the two-dimensional heat conduction equation, $\nabla^{2} T=$ 0 , for the assigned convective boundary conditions on the hot and cold sides and symmetric boundary conditions on the right and left boundaries where a rib-roughened wall repeats itself. Temperature field for a typical geometry and for one set of assigned boundary conditions is shown in Figure 3. Once the temperature field was calculated, the total heat transfer rate from the gas to the coolant side was determined by

$$
\dot{Q}_{\text {num }}=h_{\text {hot }} \sum_{i=1}^{n} l_{i}\left(T_{\text {hot }}-T_{s, i}\right) \text {, }
$$

where $n$ is the number of finite elements on the hot side of the numerical model and $T_{s, i}$ is the surface temperature of the $i$ th element on the gas side. Note that

$$
\sum_{i=1}^{n} l_{i}=P
$$

The corrected heat transfer coefficient was then calculated by equating $(8)$ and $(9)$ to obtain $\left(\dot{Q}_{\text {design }}=\dot{Q}_{\text {num }}\right)$ :

$$
h_{\text {corrected }}=\frac{1}{\left(P\left(T_{\text {hot }}-T_{\text {cold }}\right) / \dot{Q}_{\text {num }}\right)-\left(R_{\text {hot }}+R_{\text {wall }}\right)} .
$$

The reported correction factor for the rib fin effect is defined as

$$
\text { Correction factor }=\frac{h_{\text {corrected }}}{h_{\text {overall }}}=\frac{N u_{\text {corrected }}}{N u_{\text {overall }}}=\frac{E F_{\text {corrected }}}{E F_{\text {overall }}} \text {. }
$$




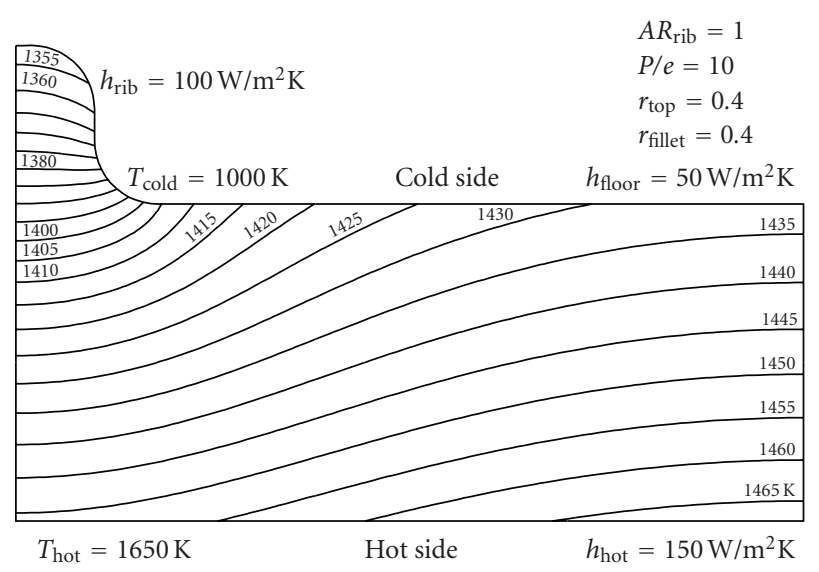

Figure 3: Temperature contours for a typical case.

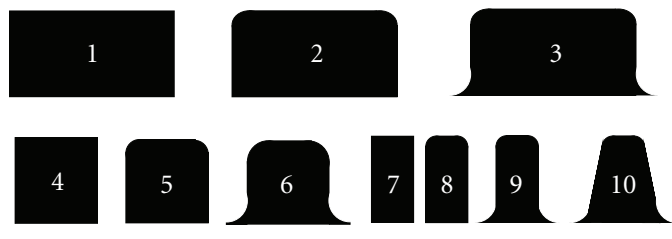

Figure 4: Analyzed rib geometries.

Figure 4 and Table 1 show all the geometries that were analyzed. Four rib aspect ratios $(0.5,1,1.33$, and 2$)$ were investigated at four pitch-to-height ratios of 5, 7.5, 10, and 12.5. Each case was run for all sharp as well as round top corners and fillets. The range of the chosen parameters are believed to cover many of today's designs.

\section{RESULTS AND DISCUSSION}

The first step in this investigation was to determine which parameters were dominant in rib fin effects. Earlier runs revealed that $T_{\text {cold }}, T_{\text {hot }}$, and $h_{\text {hot }}$ had little effects on the correction factor. The effects of $t_{\text {wall }}$ and $k_{\text {metal }}$ within the range of today's designs were also negligible. Therefore, these parameters were eliminated from the list of pertinent parameters. Details of all numerical analyses are given in Taslim et al. [18]. The following figures, representing a total of 386 runs, show the variation of the correction factor with respect to different parameters for some selected geometries. The practical ranges of these parameters were determined in consultation with our industrial partners. They were

$$
\begin{aligned}
& \left(T_{\text {hot }}-T_{\text {cold }}\right): 700 \text { to } 1000 \mathrm{~K} \text {, } \\
& T_{\text {hot }}: 1450 \text { to } 1650 \mathrm{~K}, \\
& h_{\text {hot }}: 35 \text { to } 280 \mathrm{~W} / \mathrm{m}^{2} \mathrm{~K}, \\
& h_{\text {rib }}: 88 \text { to } 212 \mathrm{~W} / \mathrm{m}^{2} \mathrm{~K}, \\
& h_{\text {floor }}: 22 \text { to } 88 \mathrm{~W} / \mathrm{m}^{2} \mathrm{~K}, \\
& k_{\text {metal }}: 5 \text { to } 9 \mathrm{~W} / \mathrm{mK} .
\end{aligned}
$$

\begin{tabular}{|c|c|}
\hline$A R_{\text {rib }}$ corners & b geometry \\
\hline 0.5 sharp & 1 \\
\hline$\square 0.5$ round top corners & 2 \\
\hline$\triangle 0.5$ round top corners \& fillets & 3 \\
\hline 1 sharp & 4 \\
\hline - 1 round top corners & 5 \\
\hline$\Delta 1$ round top corners \& fillets & 6 \\
\hline+2 sharp & 7 \\
\hline$\times 2$ round top corners & 8 \\
\hline * 2 round top corners \& fillets & 9 \\
\hline$\diamond 1.333$ trapezoid & 10 \\
\hline
\end{tabular}

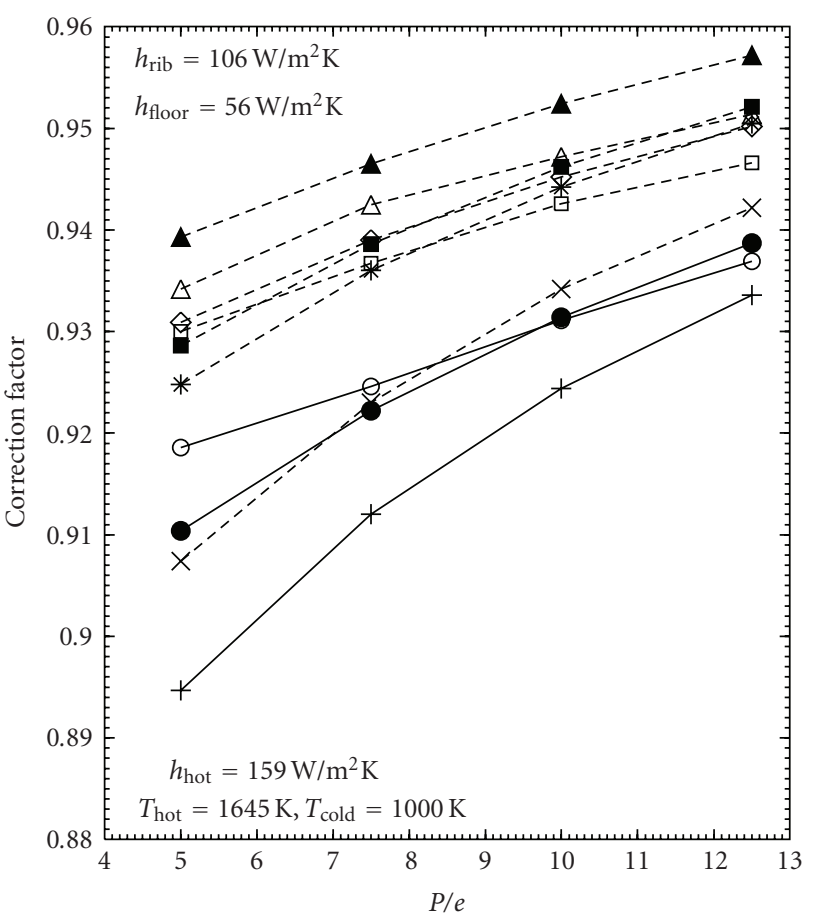

Figure 5: Correction factor variation with $P / e$.

Figure 5 shows the variation of the correction factor with the rib pitch-to-height ratio, $P / e$, for three rib aspect ratios. Each rib geometry is run for three cases of all sharp corners, round top corners with no fillets and round top corners with fillets. The general trend is that the correction factor increases with $P / e$ and with the rounding of top corners and presence of fillets for all cases. This behavior is expected since higher pitch-to-height ratios correspond to less number of ribs per given area and, as a result, less rib fin effects on the overall heat transfer coefficient. Rib aspect ratio of 1 at $P / e=12.5$ had the highest correction factor while the rib aspect ratio of 2 at $P / e=5$ had the lowest correction factor.

Figure 6 shows the variation of correction factor with $h_{\text {floor }}$ and $h_{\text {rib }}$ for a typical rib geometry representing a rectangular rib of aspect ratios 1 with sharp as well as round corners. The general behavior is the same for all cases as they are presented in Taslim [25]. The correction factor increases with $h_{\text {floor }}$ and decreases with $h_{\text {rib }}$. A physical explanation for this behavior is that higher rib heat transfer coefficients correspond to higher convective heat transfer from the rib surface to the coolant and, as a result, higher temperature 
TABLE 1: Geometric specifications.

\begin{tabular}{l|c|c|c|c|c|c}
\hline $\mathrm{AR}_{\text {rib }}$ & $P / e$ & $r_{\text {top }} / e$ & $r_{\text {fillet }} / e$ & $h_{\text {rib }}\left(\mathrm{W} / \mathrm{m}^{2} \mathrm{~K}\right)$ & $h_{\text {floor }}\left(\mathrm{W} / \mathrm{m}^{2} \mathrm{~K}\right)$ & Geometry \\
\hline 0.5 & $5,7.5,10,12.5$ & $0,0.4$ & $0,0.4$ & $88-212$ & $22-88$ & $1,2,3$ (Figure 4$)$ \\
1 & $5,7.5,10,12.5$ & $0,0.4$ & $0,0.4$ & $88-212$ & $22-88$ & $4,5,6$ (Figure 4$)$ \\
1.333 & $5,7.5,10,12.5$ & $0,0.4$ & $0,0.4$ & $88-212$ & $22-88$ & 10 (Figure 4$)$ \\
2 & $5,7.5,10,12.5$ & $0,0.4$ & $0,0.4$ & $88-212$ & $22-88$ & $7,8,9$ (Figure 4$)$ \\
\hline \multicolumn{2}{l}{$T_{\text {cold }}$} \\
\hline
\end{tabular}

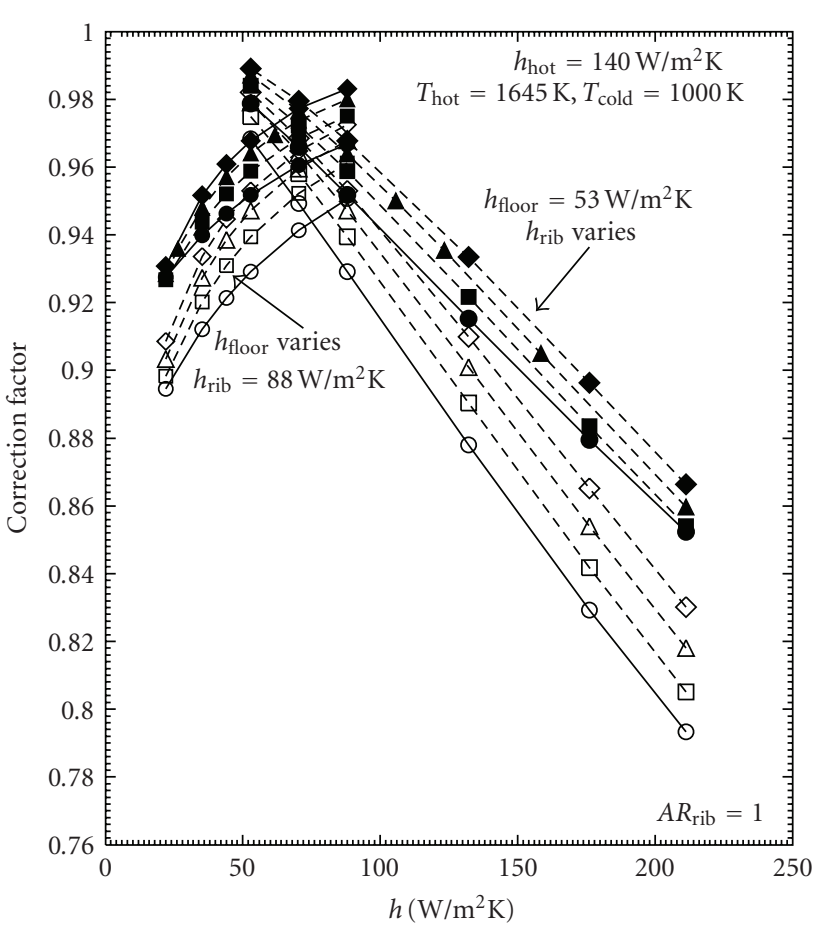

P/e rib geometry

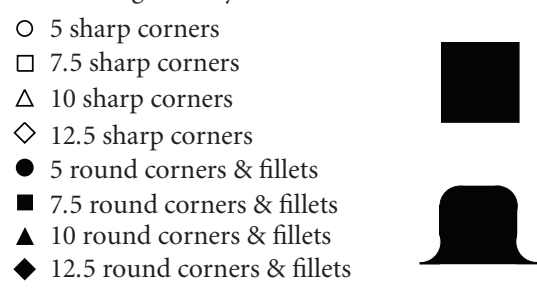

FIgURE 6: Correction factor variation with $h_{\text {rib }}$ and $h_{\text {floor }}$ for a rib aspect ratio of 1 .

difference between the rib surface and rib base. Furthermore, the ribs with round corners and fillets produce higher correction factors than those of sharp corners and, as it was shown in Figure 5, the correction factor increases with the rib pitchto-height ratio. It should be noted that a higher correction factor means that the rib surface temperature is less affected by the rib fin effect.

Figure 7 represents the results of all 386 cases that were analyzed. High aspect ratio rib cases $\left(\mathrm{AR}_{\text {rib }}=2\right)$ with sharp corners have the lowest correction factor since, geometrically, they are closer to conventional fins and, as a result, fin effects are more pronounced. The low aspect ratio rib cases specially

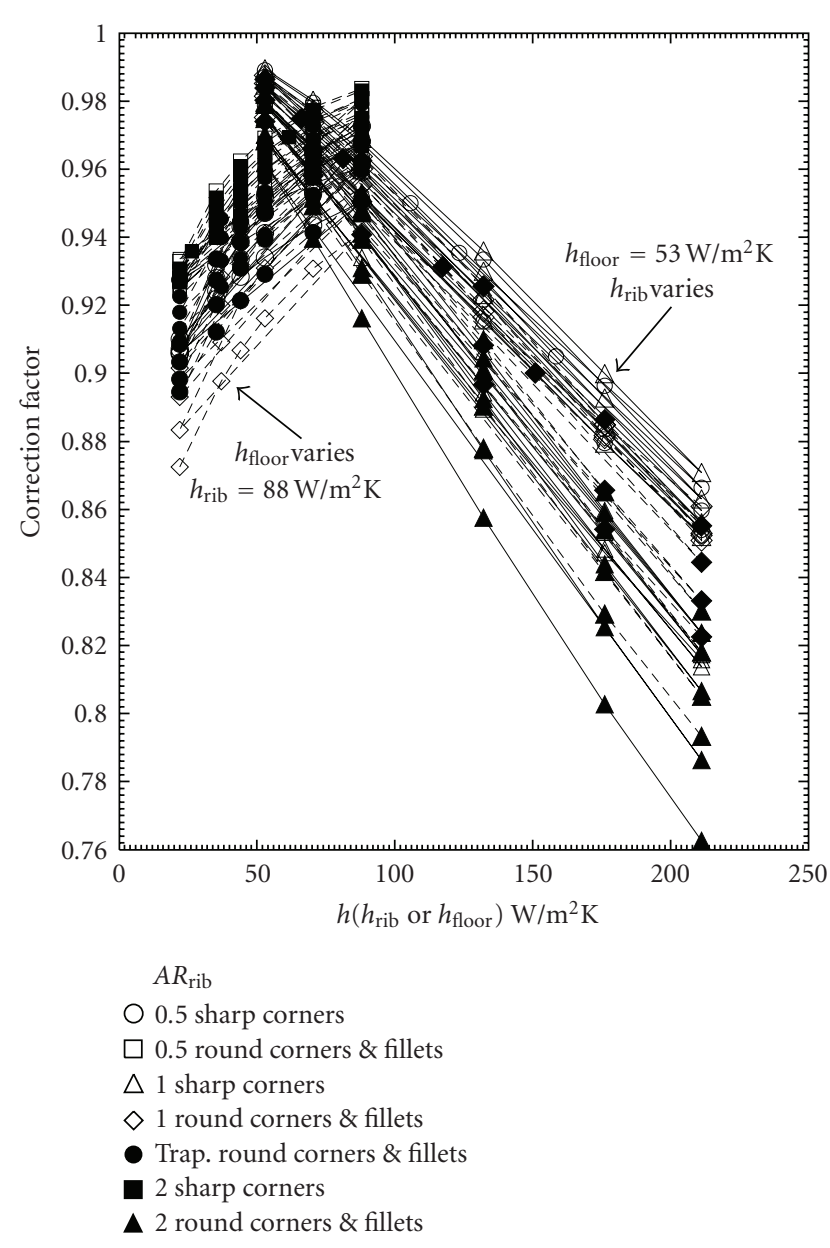

FIgURE 7: Correction factor variation with $h_{\text {rib }}$ and $h_{\text {floor }}$ for all rib geometries.

with round corners and fillets have the highest correction factors, that is, less fin effects since, geometrically, they are far from conventional fins.

The next major task was to develop a correlation that would encompass all pertinent parameters affecting the correction factor. For the development of an effective statistical model to account for the influence of the pertinent nondimesional parameters on output function, the Group method of data handling (GMDH) was used. This method (Ivakhnenko [26], Ivakhnenko and Yurachkovsky [27]) is intended for data files with a limited number of experimental points. It permits combining the influence of all important 
TABLE 2: Randomly chosen data points.

\begin{tabular}{|c|c|c|c|c|c|c|c|}
\hline Number & $P / e$ & $R_{\text {top }} / e$ & $R_{\text {fillet }} / e$ & $\mathrm{AR}_{\mathrm{ri}}$ & $h_{\text {rib }}$ & $h_{\text {floor }}$ & $Y$ \\
\hline 1 & 5 & 0 & 0 & 0.5 & 500 & 125 & 0.9100 \\
\hline 2 & 5 & 0 & 0 & 0.5 & 500 & 200 & 0.9218 \\
\hline 3 & 7.5 & 0 & 0 & 0.5 & 1000 & 300 & 0.8483 \\
\hline 4 & 7.5 & 0 & 0 & 0.5 & 400 & 300 & 0.9592 \\
\hline 5 & 7.5 & 0 & 0 & 0.5 & 500 & 125 & 0.9061 \\
\hline 6 & 10 & 0 & 0 & 0.5 & 500 & 250 & 0.9386 \\
\hline 7 & 12.5 & 0 & 0 & 0.5 & 750 & 300 & 0.9065 \\
\hline 8 & 12.5 & 0 & 0 & 0.5 & 500 & 300 & 0.9520 \\
\hline 9 & 12.5 & 0 & 0 & 0.5 & 300 & 300 & 0.9824 \\
\hline 10 & 12.5 & 0 & 0 & 0.5 & 500 & 250 & 0.9432 \\
\hline 11 & 5 & 0.4 & 0.4 & 0.5 & 750 & 300 & 0.9165 \\
\hline 12 & 7.5 & 0.4 & 0.4 & 0.5 & 500 & 250 & 0.9493 \\
\hline 13 & 10 & 0.4 & 0.4 & 0.5 & 500 & 250 & 0.9528 \\
\hline 14 & 12.5 & 0.4 & 0.4 & 0.5 & 500 & 400 & 0.9741 \\
\hline 15 & 5 & 0 & 0 & 1 & 608 & 317 & 0.9104 \\
\hline 16 & 12.5 & 0 & 0 & 1 & 608 & 317 & 0.9387 \\
\hline 17 & 7.5 & 0.4 & 0.4 & 1 & 608 & 317 & 0.9465 \\
\hline 18 & 5 & 0 & 0 & 1 & 500 & 200 & 0.9121 \\
\hline 19 & 7.5 & 0 & 0 & 1 & 500 & 400 & 0.9522 \\
\hline 20 & 10 & 0 & 0 & 1 & 500 & 300 & 0.9471 \\
\hline 21 & 10 & 0.4 & 0.4 & 1 & 400 & 300 & 0.9767 \\
\hline 22 & 10 & 0.4 & 0.4 & 1 & 400 & 300 & 0.9765 \\
\hline 23 & 10 & 0.4 & 0.4 & 1 & 400 & 300 & 0.9765 \\
\hline 24 & 12.5 & 0 & 0 & 1 & 750 & 300 & 0.9099 \\
\hline 25 & 12.5 & 0 & 0 & 1 & 500 & 300 & 0.9530 \\
\hline 26 & 5 & 0.4 & 0.4 & 1 & 500 & 300 & 0.9518 \\
\hline 27 & 7.5 & 0.4 & 0.4 & 1 & 750 & 300 & 0.9216 \\
\hline 28 & 10 & 0.4 & 0.4 & 1 & 300 & 300 & 0.9871 \\
\hline 29 & 10 & 0.4 & 0.4 & 1 & 500 & 250 & 0.9570 \\
\hline 30 & 10 & 0.4 & 0.4 & 1 & 500 & 350 & 0.9693 \\
\hline 31 & 12.5 & 0.4 & 0.4 & 1 & 500 & 250 & 0.9609 \\
\hline 32 & 5 & 0.2 & 0.4 & 1.5 & 1000 & 300 & 0.8795 \\
\hline 33 & 5 & 0.2 & 0.4 & 1.5 & 750 & 300 & 0.9150 \\
\hline 34 & 5 & 0.2 & 0.4 & 1.5 & 400 & 300 & 0.9666 \\
\hline 35 & 7.5 & 0.2 & 0.4 & 1.5 & 300 & 300 & 0.9847 \\
\hline 36 & 7.5 & 0.2 & 0.4 & 1.5 & 500 & 125 & 0.9276 \\
\hline 37 & 10 & 0.2 & 0.4 & 1.5 & 1200 & 300 & 0.8631 \\
\hline 38 & 10 & 0.2 & 0.4 & 1.5 & 400 & 300 & 0.9773 \\
\hline 39 & 10 & 0.2 & 0.4 & 1.5 & 500 & 250 & 0.9583 \\
\hline 40 & 12.5 & 0.2 & 0.4 & 1.5 & 750 & 300 & 0.9360 \\
\hline 41 & 12.5 & 0.2 & 0.4 & 1.5 & 500 & 400 & 0.9781 \\
\hline 42 & 5 & 0 & 0 & 2 & 750 & 300 & 0.8576 \\
\hline 43 & 5 & 0 & 0 & 2 & 500 & 300 & 0.9162 \\
\hline 44 & 5 & 0 & 0 & 2 & 500 & 500 & 0.9416 \\
\hline 45 & 7.5 & 0 & 0 & 2 & 1200 & 300 & 0.7863 \\
\hline 46 & 7.5 & 0 & 0 & 2 & 500 & 250 & 0.9213 \\
\hline 47 & 7.5 & 0 & 0 & 2 & 500 & 300 & 0.9309 \\
\hline 48 & 10 & 0 & 0 & 2 & 750 & 300 & 0.8925 \\
\hline 49 & 10 & 0 & 0 & 2 & 500 & 250 & 0.9319 \\
\hline 50 & 12.5 & 0 & 0 & 2 & 400 & 300 & 0.9646 \\
\hline
\end{tabular}


TABle 2: Continued.

\begin{tabular}{lccccccc}
\hline Number & $P / e$ & $R_{\text {top }} / e$ & $R_{\text {fillet }} / e$ & $\mathrm{AR}_{\text {ri }}$ & $h_{\text {rib }}$ & $h_{\text {floor }}$ & $Y$ \\
\hline 51 & 5 & 0.2 & 0.4 & 2 & 500 & 200 & 0.9254 \\
52 & 7.5 & 0.2 & 0.4 & 2 & 500 & 500 & 0.9695 \\
53 & 10 & 0.2 & 0.4 & 2 & 666.7 & 300 & 0.9313 \\
54 & 10 & 0.2 & 0.4 & 2 & 500 & 250 & 0.9498 \\
55 & 10 & 0.2 & 0.4 & 2 & 500 & 300 & 0.9574 \\
56 & 10 & 0.2 & 0.4 & 2 & 500 & 400 & 0.9682 \\
57 & 10 & 0.2 & 0.4 & 2 & 500 & 500 & 0.9753 \\
58 & 12.5 & 0.2 & 0.4 & 2 & 1200 & 300 & 0.8552 \\
59 & 12.5 & 0.2 & 0.4 & 2 & 1000 & 300 & 0.8864 \\
60 & 12.5 & 0.2 & 0.4 & 2 & 500 & 400 & 0.9727 \\
\hline
\end{tabular}

TABLE 3: Test points.

\begin{tabular}{l|c|c|c|c|c|c|c}
\hline Number & $P / e$ & $R_{\text {top }} / e$ & $R_{\text {fillet }} / e$ & $\mathrm{AR}_{\mathrm{ri}}$ & $h_{\text {rib }}$ & $h_{\text {floor }}$ & $Y$ \\
\hline 1 & 12.5 & 0.4 & 0.4 & 0.5 & 500 & 500 & 0.9805 \\
2 & 5 & 0.4 & 0.4 & 1 & 300 & 300 & 0.9840 \\
3 & 7.5 & 0.2 & 0.4 & 2 & 608 & 317 & 0.9442 \\
4 & 7.5 & 0.2 & 0.4 & 2 & 1200 & 300 & 0.8331 \\
5 & 7.5 & 0.2 & 0.4 & 2 & 500 & 125 & 0.9226 \\
\hline
\end{tabular}

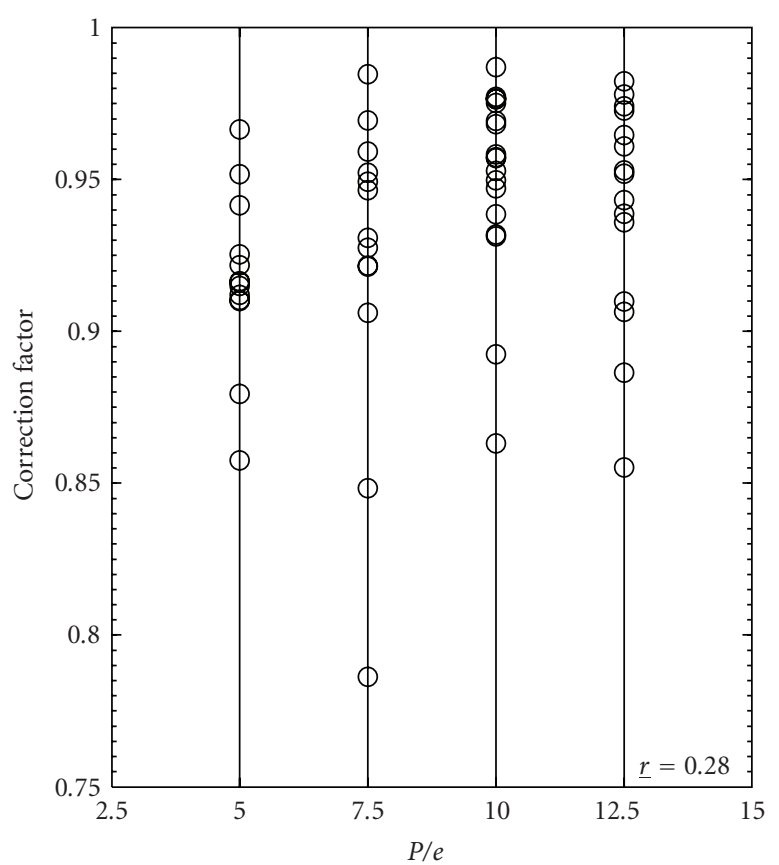

FIgURE 8: Correction factor variation with $P / e$ for the set of chosen data.

parameters in the entire structural form of the correlation. Since this method is not very known and widely used, it is necessary to describe it in brief.

The GMDH is an original method for obtaining mathematical models for problems of structural-parametric identification, or performing simulations on the basis of ex-

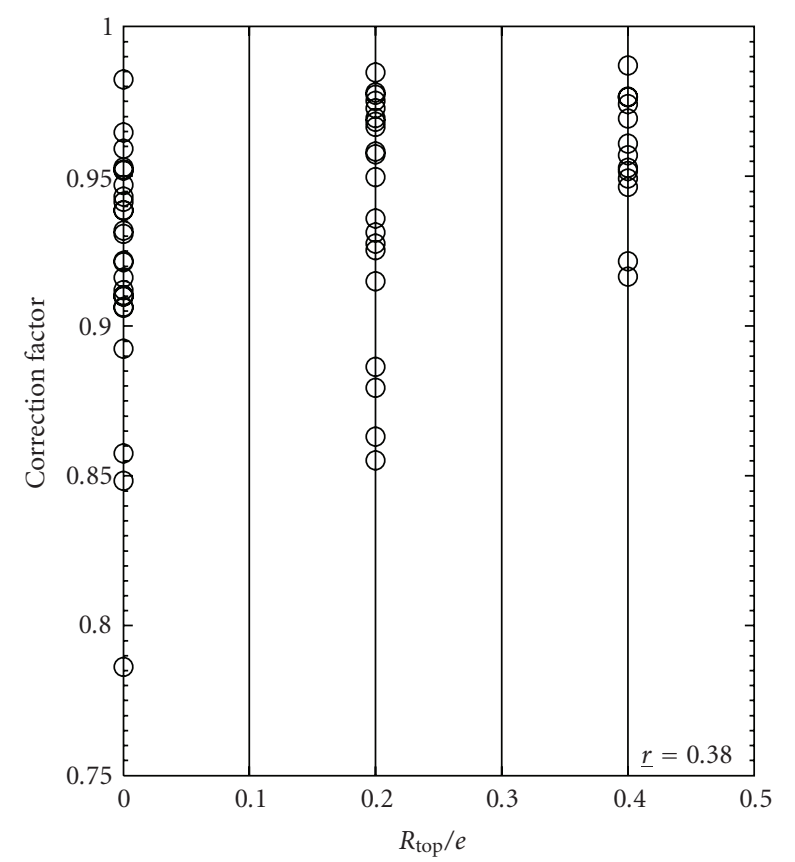

FIGURE 9: Correction factor variation with $R_{\mathrm{top}} / e$ for the set of chosen data.

perimental data with uncertainty. Such problems consist of obtaining mathematical models which approach unknown functional relationships between different parameters (objects) in a process. The available information about these relationships is presented in implicit forms within a sample (file) of existing data. The GMDH differs from other 


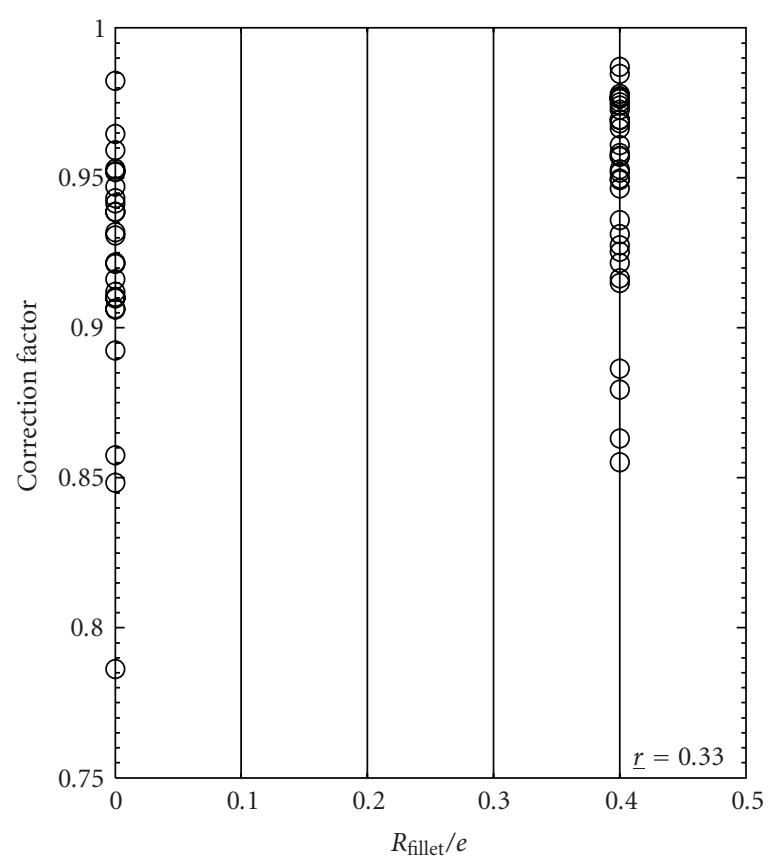

Figure 10: Correction factor variation with $R_{\text {fillet }} / e$ for the set of chosen data.

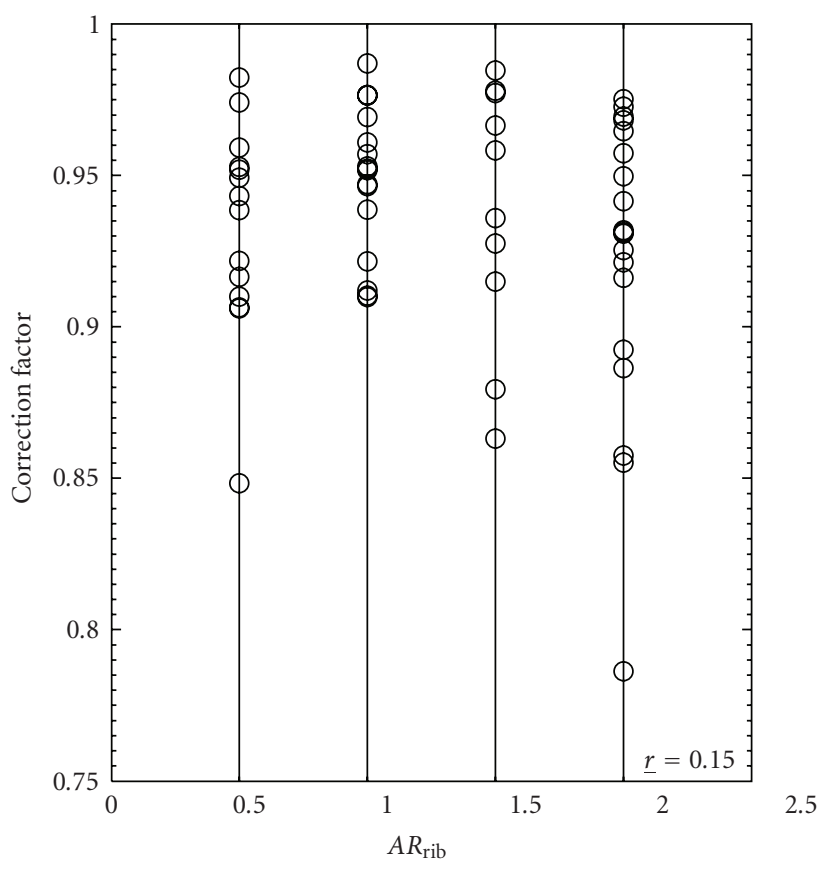

FIGURE 11: Correction factor variation with $\mathrm{AR}_{\text {rib }}$ for the set of chosen data.

methods by the application of the principles of automatic generation of variants-inconclusive solutions, and by successive selection with the help of external criteria for the definition of models of optimal complexity. The GMDH relates to the group of methods of "cross-model validation" (as distinct from methods of applied regression analysis and

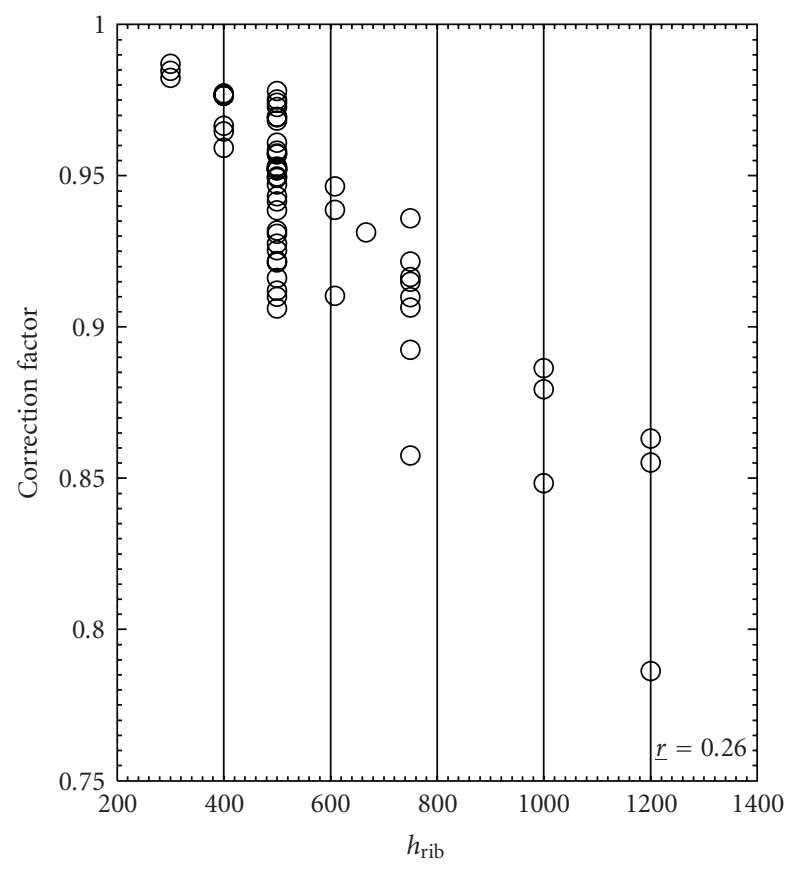

FIGURE 12: Correction factor variation with $h_{\text {rib }}$ for the set of chosen data.

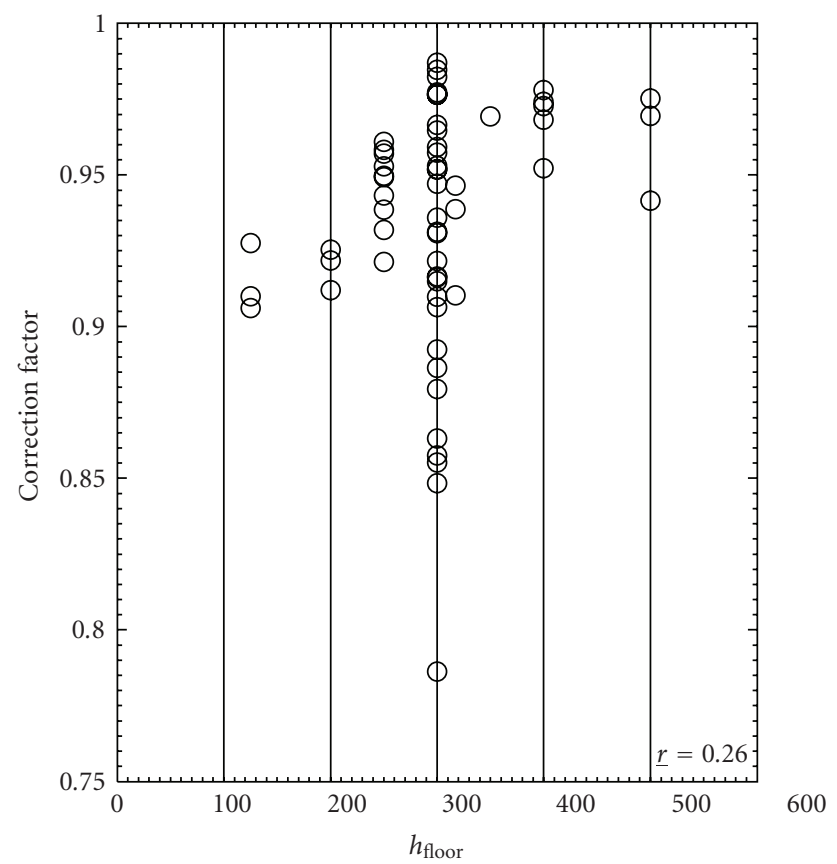

FIGURE 13: Correction factor variation with $h_{\text {floor }}$ for the set of chosen data.

methods "with explicit limitation of model complexity") for the solution of simulation problems. The GMDH procedure consists of the optimization of the model structure and parameters with the help of expedient enumeration of possibilities for automatically generated model variants within the set class of basic models and with the help of external criteria 


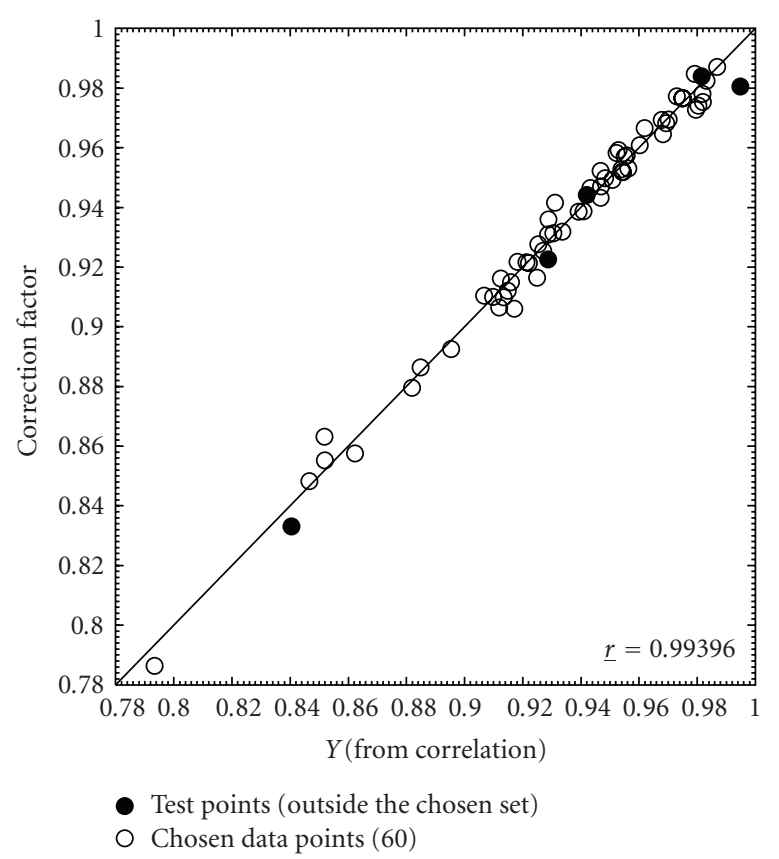

FIgURE 14: Comparison of actual versus correlated data.

based on a sample fragmentation. Using the GMDH algorithms, it is possible to simulate static objects, time series, and dynamic objects (processes) within the following main classes of models: linear, polynomial, additive-multiplicative, harmonic, autoregressive, and so forth, to name a few. During enumeration of model possibilities, it may be convenient to use generators of structures of enumerating and multiseries types. In this procedure, the last ones are completely original, and the first ones in some particular cases (under abandoned principle of inconclusive solutions, or freedom of choice) emulate the procedures of test of all regressions, branches and bounds, or step-by-step regression. Therefore, the GMDH is designed for models definition of technical, technological, ecological, and other complex objects and processes using experimental data under the condition of uncertainty, featured by limited numbers of noise observations, incomplete information about structure of significant variables, and internal correlations of object (process). Several successful examples of the GMDH, applied to turbomachines, are explained in Nezym et al. [28, 29].

\section{RIB FIN STATISTICAL MODEL BASED ON THE GMDH ALGORITHM}

Initial data for the model development (60 out of 386 experimental points), shown in Table 2, were chosen with the help of the table of random numbers. Individual influence of the six proposed arguments $\left(P / e, R_{\text {top }} / e, R_{\text {fillet }} / e, \mathrm{AR}_{\text {rib }}\right.$, $h_{\text {rib }}$, and $h_{\text {floor }}$ ) on function $Y$ (correction factor) are presented in Figure 8 through Figure 13. It should be noted that there are 60 data points in each figure. However, some of them are coinciding or are very close to each other for the scale of the plots. All these functions are nonlinear, as corre- lation coefficient $r$ is significantly less than 1 (in the range of 0.15 to 0.38$)$.

\subsection{Development of the model}

A multiseries algorithm with the orthogonalization of the principal members was selected. The orthogonality of the model members permits the user to determine the highest degree of the model with $N$ experimental data points. A high-degree polynomial was found as a support function. For identification of optimal structure of the model formula, a consistency criterion in the form of minimum shift, Ivakhnenko and Yurachkovsky [27], was used at the base of analysis of solution:

$$
\eta_{c c}^{2}=\frac{\sum_{j=1}^{N}\left(Y_{A}-Y_{B}\right)_{j}^{2}}{\sum_{j=1}^{N}\left(Y_{j}^{*}\right)^{2}},
$$

where

(i) $\eta_{c c}^{2}$ is consistency criterion;

(ii) $Y_{A}$ is an output value of the model, based on the estimated coefficients of subsample $A$;

(iii) $Y_{B}$ is an output value of the model, based on the estimated coefficients of subsample $B$, and under the condition of $N_{A}+N_{B}=N$;

(iv) $Y_{j}^{*}$ is the given data in Table 2 .

An external criterion for stability was used and with the application of the GMDH algorithm, the model formula was obtained in the following form:

$$
\begin{aligned}
y= & 1.01138-1.83878 \times 10^{-4} h_{\text {rib }}+1.44299 \times 10^{-5}(P / e) h_{\text {floor }} \\
+ & 7.34671 \times 10^{-4}\left(R_{\text {fillet }} / e\right) h_{\text {rib }} /(P / e)-8.93306 \mathrm{AR}_{\text {rib }} / \\
& {\left[(P / e) h_{\text {floor }}\right]-1.59563 \times 10^{-3}(P / e) h_{\text {floor }} / h_{\text {rib }} } \\
- & 9.79612 \times 10^{-3}\left[\mathrm{AR}_{\text {rib }} h_{\text {rib }}\right] /\left[(P / e) h_{\text {floor }}\right] \\
- & 1.38097 \times 10^{-3} / \mathrm{AR}_{\text {rib }}^{2}-6.27083 \times 10^{-6} \mathrm{AR}_{\text {rib }}^{3} h_{\text {rib }} /(P / e)
\end{aligned}
$$

with

(i) criterion: stability,

(ii) number of series: 8 ,

(iii) standard deviation $=0.00432$,

(iv) correlation coefficient $r=0.999990$,

(v) maximum relative error $=-1.31 \%$ for data point 37 ,

(vi) standard relative error $=0.47 \%$.

The calculated correction factors using the proposed correlation (14) are compared with those of Table 2 in Figure 14. A maximum relative error of $-1.31 \%$ for point number 37 was calculated. The solid symbols in that figure demonstrate the model test points (not used for the simulation). These five test points, shown in Table 3, were chosen with the help of the table of random numbers.

\section{CONCLUSIONS}

Group method of data handling, a self-organizing method, was used to correlate the parameters affecting the fin efficiency of the ribs in cooling cavities of turbine airfoils or 
on heat exchangers surfaces. Major conclusions of this study were the following.

(1) Rib fin effects should be taken into consideration in the design of airfoil cooling circuits, heat exchangers, and thermal systems when, in using the software design tools, details of rib geometry and variations of heat transfer coefficients are replaced by an equivalent heat transfer coefficient.

(2) Evidenced by the accuracy of the model (standard deviation: 0.00432 , standard relative error: $0.47 \%$, correlation coefficient: 0.99396$), \mathrm{GMDH}$ is a powerful tool for the correlation of data with complex interrelated parameters.

\section{NOMENCLATURE}

a: $\quad$ Channel width (Figure 1)

$A_{\text {base }}$ Rib base area (Figure 1)

$A_{\text {floor: }}$ Heat transfer area between two ribs

$A_{\text {rib: }} \quad$ Rib total exposed heat transfer area

AR: $\quad$ Channel aspect ratio

$\mathrm{AR}_{\text {rib }}: \quad$ Rib aspect ratio $\left(2 e /\left(w_{\text {top }}+w_{\text {bot }}\right)\right)$

$D_{h}: \quad$ Channel hydraulic diameter

$e$ : $\quad$ Rib height

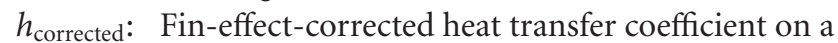
rib-roughened surface (13)

$h_{\text {equiv }}$ Rib equivalent heat transfer coefficient (4)

$h_{\text {floor }}$ Average heat transfer coefficient on the surface between a pair of ribs

$h_{\text {hot }}$ : Hot side average heat transfer coefficient

$h_{\text {overall }}$ Overall area-weighted average heat transfer coefficient on a rib and on the surface between a pair of ribs

$h_{\text {rib }}$ Average heat transfer coefficient on the rib surface

$h_{\text {smooth: }}$ Fully developed heat transfer coefficient in a smooth channel

$k_{\text {metal }}$ : Rib-roughened wall thermal conductivity

$l_{i}$ : $\quad$ Finite element cell width on the gas side boundary

$n$ : $\quad$ Number of finite element cells on the gas side boundary

$N u_{\text {smooth }}$ : Nusselt number for a fully developed flow in a smooth channel

$P: \quad$ Rib pitch (center to center)

$\dot{Q}_{\text {design }}: \quad$ Heat transfer from the gas to the coolant calculated by blade design software tools (Figure 2)

$\dot{Q}_{\text {num }}$ : Heat transfer from the gas to the coolant calculated from numerical models (Figure 2)

$r: \quad$ Correlation coefficient

$r_{\text {fillet }}$ : Fillet radius

$r_{\text {top }}$ : Rib top corner radius

$R_{\text {corrected: }}$ Equivalent coolant side thermal resistance

$R_{\text {hot }}$ : Hot side thermal resistance
$R_{\text {wall }}$ : Rib-roughened wall thermal resistance $P$ rib pitch (center to center)

$t_{\text {wall }}$ Rib-roughened wall thickness

$T_{f}$ : Film temperature

$T_{\text {cold }}$ : Cold side average temperature

$T_{\text {hot }}$ : Hot side average temperature

$T_{s}$ : $\quad$ Surface temperature

$w_{\text {top }}$ : Rib top width

$w_{\text {bot }}$ : Rib bottom width

$y: \quad$ Correction factor defined by (14)

$\alpha: \quad$ Rib angle of attack

$\beta$ : $\quad$ Rib top angle (Figure 1)

\section{REFERENCES}

[1] N. Abuaf, R. Gibbs, and R. Baum, "Pressure drop and heat transfer coefficient distributions in serpentine passages with and without turbulence promoters," in Proceedings of the 8th International Heat Transfer Conference, C. L. Tien, V. P. Carey, and J. K. Ferrell, Eds., vol. 6, pp. 2837-2845, San Francisco, Calif, USA, August 1986.

[2] F. Burggraf, "Experimental heat transfer and pressure drop with two dimensional turbulence promoters applied to two opposite walls of a square tube," in ASME, Augmentation of Convective Heat and Mass Transfer, A. E. Bergles and R. L. Webb, Eds., pp. 70-79, New York, NY, USA, 1970.

[3] P. R. Chandra, J. C. Han, and S. C. Lau, "Effect of rib angle on local heat/mass transfer distribution in a two-pass ribroughened channel," in ASME, International Gas Turbine Conference and Exhibition, p. 9, Anaheim, Calif, USA, May-June 1987.

[4] P. R. Chandra and J. C. Han, "Pressure drop and mass transfer in two-pass ribbed channels," Journal of Thermophysics and Heat Transfer, vol. 3, no. 3, pp. 315-319, 1989.

[5] J. C. Han, L. R. Glicksman, and W. M. Rohsenow, "An investigation of heat transfer and friction for rib-roughened surfaces," International Journal of Heat and Mass Transfer, vol. 21, no. 8, pp. 1143-1156, 1978.

[6] J. C. Han, J. S. Park, and C. K. Lei, "Heat transfer enhancemenin channels with turbulence promoters," Journal of Engineering for Gas Turbines and Power, vol. 107, pp. 628-635, 1985.

[7] J. C. Han, Y. M. Zhang, and C. P. Lee, "Influence of surface heat flux ratio on heat transfer augmentation in square channels with parallel, crossed, and V-shaped angled ribs," Journal of Turbomachinery, vol. 114, no. 4, pp. 872-880, 1992.

[8] J. C. Han, "Heat transfer and friction in channels with two opposite rib-roughened walls," Journal of Heat Transfer, vol. 106, no. 4, pp. 774-781, 1984.

[9] T. M. Liou, J. J. Hwang, and S. H. Chen, "Turbulent heat transfer and fluid flow in a channel with repeated rib pairs," in Proceedings of the ASME/JSME Thermal Engineering Joint Conference, vol. 3, pp. 205-212, Reno, Nev, USA, March 1991.

[10] T.-M. Liou and J.-J. Hwang, "Effect of ridge shapes on turbulent heat transfer and friction in a rectangular channel," International Journal of Heat and Mass Transfer, vol. 36, no. 4, pp. 931-940, 1993.

[11] D. E. Metzger, C. S. Fan, and J. W. Pennington, "Heat transfer and flow friction characteristics of very rough transverse ribbed surfaces with and without pin fins," in Proceedings of 
the ASME/JSME Thermal Engineering Joint Conference, vol. 1, pp. 429-436, Honolulu, Hawaii, USA, March 1983.

[12] D. E. Metzger, M. K. Chyu, and R. S. Bunker, "The contribution of on-rib heat transfer coefficients to total heat transfer from rib-roughened surfaces," in Transport Phenomena in Rotating Machinery, J. H. Kim and W.-J. Yang, Eds., Hemisphere, Washington, DC, USA, 1988.

[13] D. E. Metzger, C. S. Fan, and Y. Yu, "Effects of rib angle and orientation on local heat transfer in square channels with angled roughness ribs," in Compact Heat Exchangers: A Festschrift for A.L. London, pp. 151-167, Hemisphere, Washington, DC, USA, 1990.

[14] M. E. Taslim and S. D. Spring, "Experimental investigation of heat transfer coefficients and friction factors in passages of different aspect ratios roughened with $45^{\circ}$ turbulators," in Proceedings of National Heat Transfer Conference, vol. 96, pp. 661668, Houston, Tex, USA, July 1988.

[15] M. E. Taslim and S. D. Spring, "Experimental heat transfer and friction factors in turbulated cooling passages of different aspect ratios, where turbulators are staggered," in AIAA, ASME, SAE and ASEE Joint Propulsion Conference, p. 8, Boston, Mass, USA, July 1988.

[16] M. E. Taslim and S. D. Spring, "Effects of turbulator profile and spacing on heat transfer and friction in a channel," Journal of Thermophysics and Heat Transfer, vol. 8, no. 3, pp. 555-562, 1994.

[17] M. E. Taslim, T. Li, and D. M. Kercher, "Experimental heat transfer and friction in channels roughened with angled, Vshaped, and discrete ribs on two opposite walls," Journal of Turbomachinery, vol. 118, no. 1, pp. 20-28, 1996.

[18] M. E. Taslim, T. Li, and S. D. Spring, "Measurements of heat transfer coefficients and friction factors in passages ribroughened on all walls," Journal of Turbomachinery, vol. 120, no. 3, pp. 564-570, 1998.

[19] M. E. Taslim and C. M. Wadsworth, "An experimental investigation of the rib surface-averaged heat transfer coefficient in a rib-roughened square passage," Journal of Turbomachinery, vol. 119, no. 2, pp. 381-389, 1997.

[20] G. J. Korotky and M. E. Taslim, "Rib heat transfer coefficient measurements in a rib-roughened square passage," Journal of Turbomachinery, vol. 120, no. 2, pp. 376-385, 1997.

[21] M. E. Taslim and G. J. Korotky, "Low-aspect-ratio rib heat transfer coefficient measurements in a square channel," Journal of Turbomachinery, vol. 120, no. 4, pp. 831-838, 1998.

[22] M. E. Taslim and A. Lengkong, " $45^{\circ}$ staggered rib heat transfer coefficient measurements in a square channel," Journal of Turbomachinery, vol. 120, no. 3, pp. 571-580, 1998.

[23] M. E. Taslim and A. Lengkong, " $45^{\circ}$ round-corner rib heat transfer coefficient measurements in a square channel," Journal of Turbomachinery, vol. 121, no. 2, pp. 272-280, 1999.

[24] R. L. Webb, E. R. G. Eckert, and R. J. Goldstein, "Heat transfer and friction in tubes with repeated-rib roughness," International Journal of Heat and Mass Transfer, vol. 14, no. 4, pp. 601-617, 1971.

[25] M. E. Taslim, "Rib fin effects on the overall equivalent heat transfer coefficient in a rib-roughened cooling channel," International Journal of Heat Exchangers, vol. 6, no. 2, pp. 135-152, 2005.

[26] A. G. Ivakhnenko, "Articles, papers, books and software on the Group Method of Data Handling (GMDH)," http://www.gmdh.net/articles/.

[27] A. G. Ivakhnenko and Y. P. Yurachkovsky, Complicated Systems Modelling Using Empiric Data, Radio i Svyaz, Moscow, Russia, 1987.
[28] V. Nezym, "Development of statistical model for casing treatment use," International Journal of Turbo and Jet Engines, vol. 20, no. 4, pp. 267-274, 2003.

[29] V. Nezym, J. Gomez-Mancilla, and S. V. Korkishko, "Statistical model for turning angle determination of compressor tandem cascade," in Proceedings of the 10th International Symposium on Transport Phenomena and Dynamics of Rotating Machinery, Honolulu, Hawaii, USA, March 2004. 

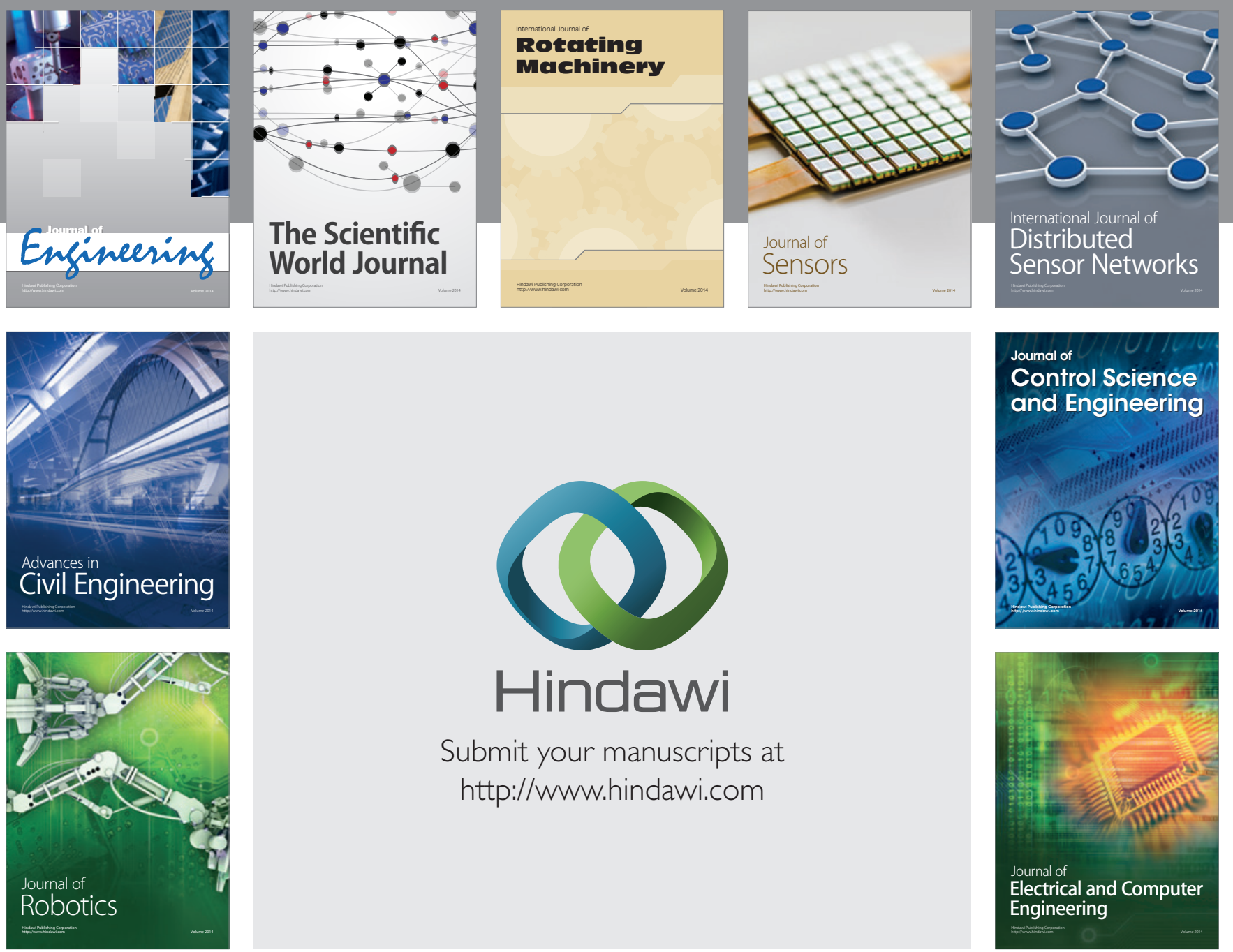

Submit your manuscripts at

http://www.hindawi.com
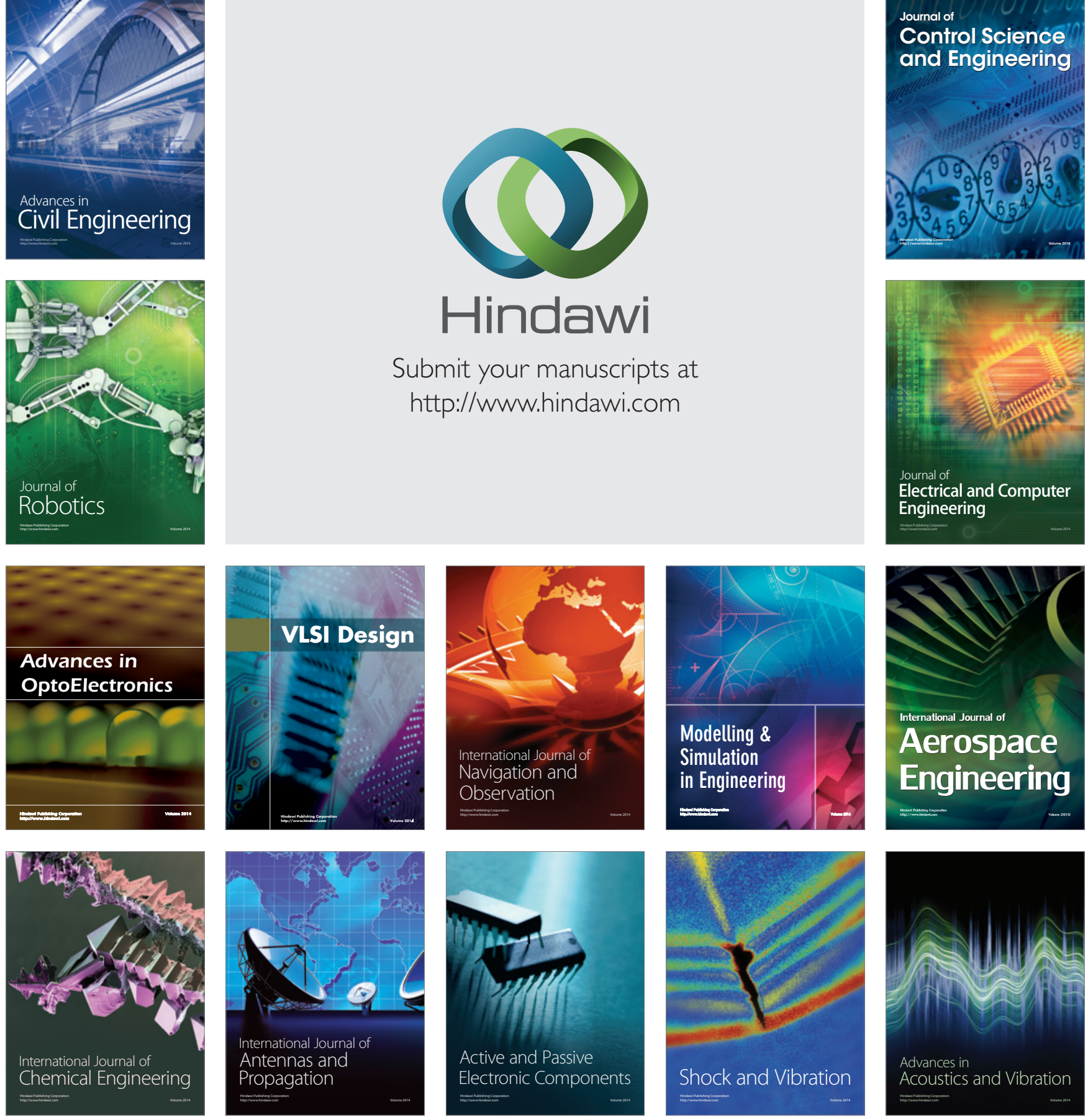